International Journal of Technology 12(1) 15-21 (2021)

Received April 2020 / Revised June 2020 / Accepted October 2020

International Journal of Technology

http://ijtech.eng.ui.ac.id

\title{
Risk Control Failure of Iron Pipes in Finished Goods Warehouses using Dynamic Systems
}

\author{
Arief Suwandi ${ }^{*}$, Teuku Yuri Zagloel ${ }^{1}$, Akhmad Hidayatno ${ }^{1}$ \\ ${ }^{1}$ Department of Industrial Engineering, Faculty of Engineering, Universitas Indonesia, Kampus UI Depok, \\ Depok 16424, Indonesia
}

\begin{abstract}
The condition of risk control failure causes many consumer complaints because many defective products are found with purchase orders for iron pipes. Storage management is very important for companies in maintaining quality and delivery accuracy for customer satisfaction. At this stage, there is a definite risk of failure from finished product control, such as material handling errors and product damage due to storage. The purpose of this research is to develop a failure risk control model in the finished goods inventory system. Iron Pipe defects are caused by poor material handling and product storage in the company. Exogenous variables from this simulation are the reliability of product handling, percentage of successful rework, and percentage of deteriorated product. The simulation results show that the optimistic scenario has the smallest defect of $0 \%$ and is followed by a most likely scenario of $1 \%$ and a pessimistic scenario of $4 \%$. The resulting model can minimize the risk of failure of iron pipe products in finished goods warehouses, and the model can be applied in more complex real-world cases.
\end{abstract}

Keywords: Deteriorated percentage of success rework; Optimistic scenario; Product handling; Warehouse

\section{Introduction}

The rapid development of science and technology requires every company to have good product quality to compete with their business competition. A quality product is something that can meet consumer expectations. Companies that produce iron pipes use steel plate raw materials which are generally used for construction, such as Pipes, Casing and Tubing, Subsea Pipes, Steel Water Pipes, Steel Pipes for Piles, and Steel Pipes for general structures. The risk control failure condition resulted in many complaints from consumers because defective products were often found in pipe purchase orders. This is a serious problem for the management of the pipeline company, and they need to immediately take corrective action to overcome the problem of defective products being manufactured (Suwandi et al., 2020).

The risk of failure to store finished products determines how the company proceeds in maintaining product quality and company sustainability. If the defect to a product is high, the company will experience losses and a lack of customer trust, resulting in serious disruption to the company (Suwartha et al., 2015). The risk of failure needs to be identified and then a model developed to reduce the failure to store the finished product 
(Kilibarda, 2013). Factors causing failure in storage include oxidation, aging, mildew, sealing failure and other slow chemical or physical processes (Liu and Liu, 2018).

The selection of the most suitable selective inspection, partial flow control, and defect correction policy is based on an analysis of the impact of actions on the overall system and the quality performance of the entire process chain, so that quality and productivity can be maintained at the system level (Grösser, Reyes-Lecuona, \& Granholm, 2017).

This study aims to design a model to control the risk of failure of iron pipe products in the finished product warehouse by using a dynamic system that can help reduce the number of damaged products produced by the company.

This study focuses on the manufacture of metal pipes, where product damage occurs due to poor storage and material mishandling.

\section{Methods}

The study was conducted using the dynamic system method. Observations are made in the warehouse where the products are ready to be distributed. The purpose of applying this method is to compare the possibility of defects in the warehouse of finished products. Dynamic systems are used to model the risk of failure products.

Dynamic systems is a simulation modeling methodology used to understand the dynamic behavior of complex systems for analyzing and solving problems that focus on policy analysis and design (Poles, 2013; Moeis et al., 2020). Dynamic systems are disciplines that are developed based on feedback control theory, decision theory, simulation technology, and computer application technology. The system thinking process created by modeling contains systematic reasoning (C. Liu, Xie, Sun, \& Chen, 2015). Forrester (1961) created a system dynamics methodology to design enterprises by treating the time-varying (dynamic) behavior of industrial organizations. The methodology is a powerful approach to obtaining insights into dynamic complexity problems (Sterman, 2000). It is designed for long-term, chronic, and dynamic management problems. Additionally, it is the proper method for approaching systems that are dynamic and full of feedback.

Stock Flow Diagram is a central concept in Dynamic Systems theory. Stock is the accumulation/collection and the characteristics of system conditions and information producers that form the basis of actions and decisions. Stocks are combined with rate or flow as information flow, so that stock becomes a source of dynamic imbalance in the system (Sterman, 2000). Model formulation is the process of translating the concept of a qualitative model into a quantitative model. In order to run, the simulation model must be complete with correct mathematical equations, parameters, and determination of the initial value conditions in the Stock Flow Diagram.

Verification aims to prove whether the models that have been made are correct. In this case, the verification technique used compares the results of simulations with manual calculations (Hidayatno et al., 2015). We can see from the units and formulations whether they are in accordance with what is desired or not. The purpose of testing is to compare the simulation behavior of the model to the actual behavior of the system. In the testing phase, the modeler must ensure that the model has a "consistency dimension" in the relationship between level, rate, and auxiliary units of variables, and the constants must make sense (Sterman, 2000).

Validation aims to see whether the output of the model created is in accordance with the desired goals and the real system. Data validation can be determined using testing methods.

a. Mean Comparison, comparing simulation results with actual data, the model is declared valid if $\mathrm{E} 1<5 \%$. 


$$
E 1=\frac{\mid \text { Simulation }- \text { Actual } \mid}{\text { Actual }}
$$

b. \% error variance, where the model will be said to be valid if E2 $<30 \%$.

$$
E 2=\frac{\mid \text { StDev Simulation }- \text { StDev Actual } \mid}{\text { StDev Actual }}
$$

c. Mean Absolute Percentage Error (MAPE), quantitative behavioral pattern comparison, where the criteria the model will be said to be valid if MAPE < 5\%: very accurate, $5 \%<$ MAPE $<10 \%$ : valid, MAPE $>10$ : not valid (Suwandi et al., 2020).

$$
M A P E=\frac{1}{n} \frac{\mid \text { Simulation-Actual } \mid}{\text { Actual }} \times 100 \%
$$

The development of dynamic models in this study uses a Dynamic Systems approach. Dynamic systems are methods for enhancing learning in complex systems (Qiao-Lun \& TieGang, 2011). The Dynamic Systems methodology building consists of two backgrounds in the traditional managerial discipline, namely cybernetics and computer simulation.The principles and concepts of these three disciplines work together by setting aside their weaknesses and solving managerial problems holistically (Grösser et al., 2017).

\subsection{Case Study}

In this section, through the illustration of the data set adopted from the case problem, the dynamic system produces a model to reduce the risk of failure of the finished products of iron pipe in the warehouse.

\subsubsection{Problem}

This case came from GM Manufacturing, located in Bekasi, Indonesia. Various types of iron pipe products are produced by this company. The problem facing the company today is that there are still defective products found in finished products in warehouses.

\subsubsection{Modeling with dynamic systems}

Physical flow describes the process of making a model (Suwandi, Zagloel, \& Hidayatno, 2018). Finished products that arrive from the shop floor are then inspected. After inspection, the finished products are sent to the warehouse. The products are stored in the warehouse until the order comes.

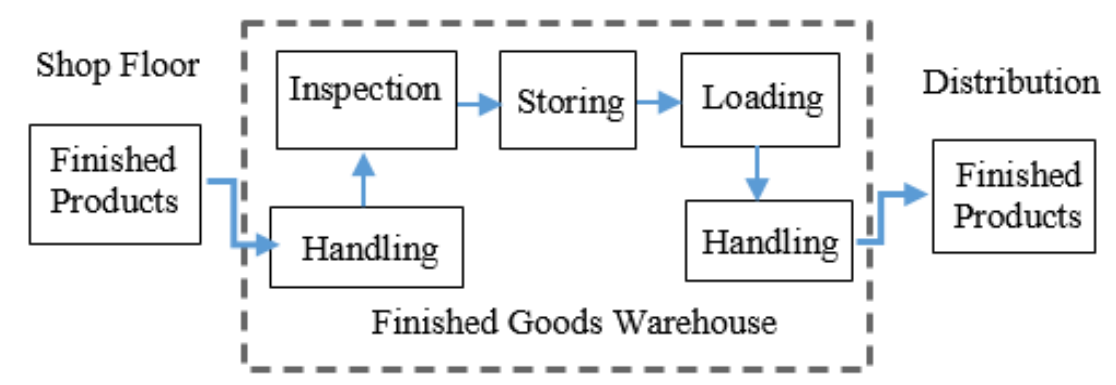

Figure 1 Physical flow of products in the warehouse

\section{Results and Discussion}

The failure risk of finished goods warehouses is reviewed by identifying physical flows, which are then developed by looking at the relationship between variables in the warehouse system. The Stock and Flow Diagram model was developed to get the best simulation results that have the lowest level of damage and the minimum risk of failure. 


\subsection{Stock Flow Diagram Results from the Failure Risk of Finished Goods Warehouse}

Stock Flow Diagram of a dynamic model of the risk of failure of the finished product in the warehouse is presented from the stock from the shop floor to the inspection, then to the allocation in the warehouse, and the good finished product becomes the product available to the customer.

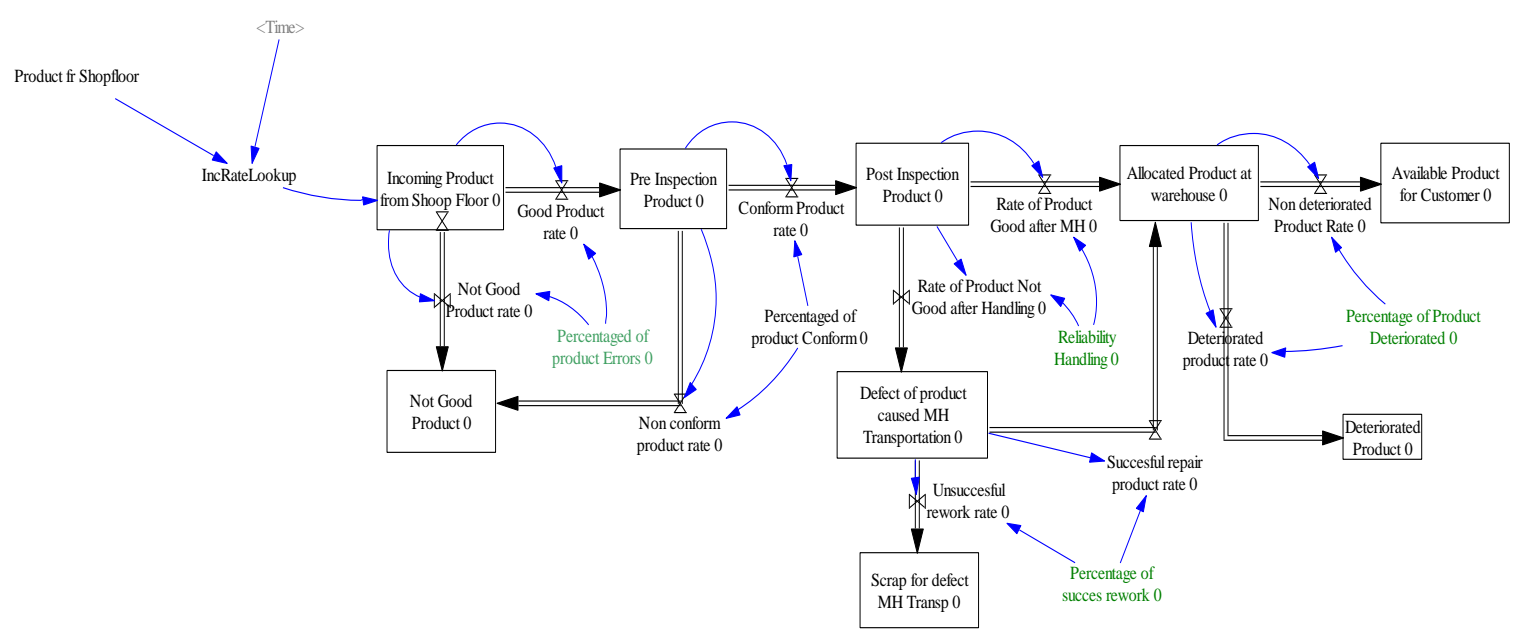

Figure 2 SFD Risks Failure of the Finished Goods in the warehouse

The process of warehousing is based on physical flow in Figure 1. In every step of the physical flow, there are several risks of defects that are caused by handling the product in moving or storage. Historical data for defective products in the warehouse can be seen in Table 1.

Table 1 Summary historical data of failure of the finished goods in the warehouse

\begin{tabular}{lcccc}
\hline \multirow{2}{*}{\multicolumn{1}{c}{ Steps on Warehousing }} & \multicolumn{2}{c}{ Summary of historical data defect per month (tons) } \\
\cline { 2 - 5 } & Average & Min & Max & Std Deviation \\
\hline Incoming Product from Shop Floor & 13,698 & 5,777 & 26,014 & 4,079 \\
Product defect caused by Handling & $222(2 \%)$ & $0(0 \%)$ & $720(4 \%)$ & $168(1 \%)$ \\
Successful Rework & $131(60 \%)$ & $0(0 \%)$ & $487(100 \%)$ & $128(31 \%)$ \\
Product Deteriorated & $209(2 \%)$ & $0(0 \%)$ & $604(4 \%)$ & $144(1 \%)$ \\
\hline
\end{tabular}

The historical data in Table 1 becomes the input of the simulation in this study. The optimistic model is obtained from the minimum defects in monthly historical data or the least from product defects, while the most likely model is obtained from the average defects on monthly historical data, and the pessimistic model is obtained from the maximum defects on monthly historical data or the most from product defects.

The exogenous variable is a variable that can be controlled, and its value is determined outside the model and imposed on the model.

Table 2 Exogenous variables on SFD risk of failure of the finished goods in the warehouse

\begin{tabular}{lccc}
\hline \multicolumn{1}{c}{ Variables } & Actual \& Most Likely & Optimistic & Pessimistic \\
\hline Mean Finished Products from shop floor & - & 13,689 tons & - \\
StDev Finished Products from shop floor & - & 4,079 tons & - \\
Reliability Product Handling & $98 \%$ & $100 \%$ & $96 \%$ \\
Percentage of Successful Rework & $60 \%$ & $100 \%$ & $0 \%$ \\
Percentage of Product Deteriorated & $2 \%$ & $0 \%$ & $4 \%$ \\
\hline
\end{tabular}




\subsection{Model Validation Results}

The results of the simulation validation are shown in Table 3.

Table 3 Model validation results

\begin{tabular}{crccc}
\hline \multirow{2}{*}{ Month } & \multicolumn{2}{c}{ Droduct Ready to } & \multicolumn{2}{c}{ MAPE } \\
\cline { 2 - 5 } & Actual & Simulation & Abs.E & Abs.E / Yt \\
\hline 16-Aug & 17,771 & 18,010 & 239 & 0.01 \\
16-Sep & 10,151 & 10,312 & 161 & 0.02 \\
16-Oct & 14,065 & 14,009 & 56 & 0 \\
16-Nov & 16,195 & 16,392 & 197 & 0.01 \\
16-Dec & 17,837 & 18,556 & 719 & 0.04 \\
17-Jan & 12,323 & 12,522 & 199 & 0.02 \\
17-Feb & 14,762 & 14,788 & 26 & 0 \\
17-Mar & 15,968 & 16,139 & 171 & 0.01 \\
17-Apr & 11,496 & 11,943 & 447 & 0.04 \\
17-May & 9,896 & 9,976 & 80 & 0.01 \\
17-Jun & 25,638 & 25,614 & 24 & 0 \\
17-Jul & 15,360 & 15,625 & 265 & 0.02 \\
17-Aug & 7,096 & 7,262 & 166 & 0.02 \\
17-Sep & 9,527 & 9,517 & 10 & 0 \\
17-Oct & 11,496 & 11,550 & 54 & 0 \\
17-Nov & 12,065 & 12,438 & 373 & 0.03 \\
17-Dec & 9,567 & 9,865 & 298 & 0.03 \\
18-Jan & 14,803 & 14,923 & 120 & 0.01 \\
18-Feb & 12,435 & 12,522 & 87 & 0.01 \\
18-Mar & 18,924 & 18,821 & 103 & 0.01 \\
18-Apr & 5,564 & 5,890 & 326 & 0.06 \\
18-May & 11,795 & 11,749 & 46 & 0 \\
\hline
\end{tabular}

\begin{tabular}{|c|c|c|c|c|}
\hline \multirow[t]{2}{*}{ Month } & \multicolumn{2}{|c|}{$\begin{array}{l}\text { Product Ready to } \\
\text { Distribute }\end{array}$} & \multicolumn{2}{|c|}{ MAPE } \\
\hline & Actual & Simulation & Abs.E & Abs.E / Yt \\
\hline 18-Jun & 15,158 & 15,470 & 312 & 0.02 \\
\hline 18-Jul & 19,747 & 19,849 & 102 & 0.01 \\
\hline 18-Aug & 9,150 & 9,778 & 628 & 0.07 \\
\hline 18-Sep & 12,554 & 12,790 & 236 & 0.02 \\
\hline $18-0 c t$ & 13,341 & 13,549 & 208 & 0.02 \\
\hline 18-Nov & 14,398 & 15,055 & 657 & 0.05 \\
\hline 18-Dec & 16,610 & 16,710 & 100 & 0.01 \\
\hline 19-Jan & 15,924 & 16,079 & 155 & 0.01 \\
\hline 19-Feb & 8,793 & 8,899 & 106 & 0.01 \\
\hline 19-Mar & 14,217 & 14,234 & 17 & 0 \\
\hline 19-Apr & 8,606 & 8,724 & 118 & 0.01 \\
\hline 19-May & 15,844 & 15,789 & 55 & 0 \\
\hline 19-Jun & 8,744 & 8,893 & 149 & 0.02 \\
\hline 19-Jul & 14,517 & 14,754 & 237 & 0.02 \\
\hline Total & 482,337 & 488,998 & - & - \\
\hline Min & 5,564 & 5,890 & - & - \\
\hline Max & 25,638 & 25,614 & - & - \\
\hline Mean & 13,398 & 13,583 & - & 0.0169 \\
\hline \multirow[t]{3}{*}{ Stdev } & \multirow{3}{*}{$\begin{array}{l}\text { E1 } \\
\text { E2 }\end{array}$} & 3,985 & - & - \\
\hline & & $1.40 \%$ & \\
\hline & & $0.60 \%$ & \multicolumn{2}{|c|}{$1.70 \%$} \\
\hline
\end{tabular}

The validation calculation shows that E1 (Mean Comparison) $=1.40 \%$, E2 (\% Error Variance) $=0.60 \%$, and MAPE (Mean Absolute Percentage Error) $=1.70 \%$. This shows that the model is declared valid because $\mathrm{E} 1<5 \%$, and $\mathrm{E} 2<20 \%$, and MAPE $<5 \%$.

\subsection{Simulation of Proposed Improvement Scenarios}

The failure risk scenario in the warehouse of finished products is based on actual data from an iron pipe manufacturing company. Exogenous simulation variables are in accordance with Table 2 .

Table 4 Simulation results of failure of the finished goods in the warehouse

\begin{tabular}{lcccccc}
\hline \multirow{2}{*}{ Process } & \multicolumn{3}{c}{ Average Output/month (ton) } & \multicolumn{2}{c}{ \% Defect } \\
\cline { 2 - 6 } & Optimistic & Most Likely & Pessimistic & Optimistic & Most Likely & Pessimistic \\
\hline Product to WH & 14,036 & 14,036 & 14,036 & - & - & - \\
Available Product at & 14,036 & 13,921 & 13,474 & $0 \%$ & $-1 \%$ & $-4 \%$ \\
WH & & & & 0 & $-1 \%$ & \\
\hline
\end{tabular}

\subsection{Cost and Benefit}

The storage costs at GM Manufacture are divided into Fixed Cost and Variable Cost. Fixed costs include rent, equipment, and employee salaries every month. The Fixed Cost is IDR 200,000,000 / month. Variable costs include electricity costs and maintenance costs. The company's variable cost is an average of $5 \%$ of the product selling price. The selling price of the product is IDR 17,000,000 / ton. The Storage variable cost is IDR 850,000 / ton product. From the three scenarios above, the average cost and benefit per month is obtained according to Table 5. 
Table 5 Cost and benefit of simulation results

\begin{tabular}{|c|c|c|c|c|c|c|}
\hline \multirow[b]{2}{*}{ Process } & \multicolumn{3}{|c|}{ TOTAL 5 Years Scenario } & \multicolumn{3}{|c|}{ Average /month } \\
\hline & Optimistic & $\begin{array}{c}\text { Most } \\
\text { Likely }\end{array}$ & Pessimistic & Optimistic & $\begin{array}{c}\text { Most } \\
\text { Likely }\end{array}$ & Pessimistic \\
\hline Product at WH (Ton) & 831,595 & 808,286 & 766,398 & 14,036 & 13,921 & 13,474 \\
\hline $\begin{array}{l}\text { Storage Cost (billion } \\
\text { IDR) }\end{array}$ & 727.8 & 722.0 & 699.2 & 12.1 & 12.0 & 11.6 \\
\hline Bruto (billion IDR) & $14,316.6$ & $14,199.9$ & $13,744.0$ & 238.6 & 236.7 & 229.1 \\
\hline $\begin{array}{l}\text { Benefit 'Bruto - Cost' } \\
\text { (billion IDR) }\end{array}$ & $13,588.8$ & $13,477.9$ & $13,044.8$ & 226.5 & 224.6 & 217.4 \\
\hline $\begin{array}{l}\text { Differences Benefit } \\
\text { with Optimistic } \\
\text { (billion IDR) }\end{array}$ & 0 & -110.9 & -544.0 & 0 & -1.8 & -9.1 \\
\hline
\end{tabular}

The cost and benefit calculation from the simulation results shows that the biggest benefit comes from the optimistic scenario with IDR 226,480,000,000 /month, then most likely with IDR $224,632,000,000 /$ month, and the last for pessimistic scenario with IDR $217,413,000,000 /$ month. From this scenario, it can be seen that if the company is not very optimistic about the risks in warehouse management, then it can lose IDR 1,848,000,000 / month for a high probability of $1 \%$ defect and $4 \%$ pessimistic defects, namely IDR 9,067,000,000.

The simulation results for 5 years ( 60 months) are shown by visualizing the simulation in Figure 3.

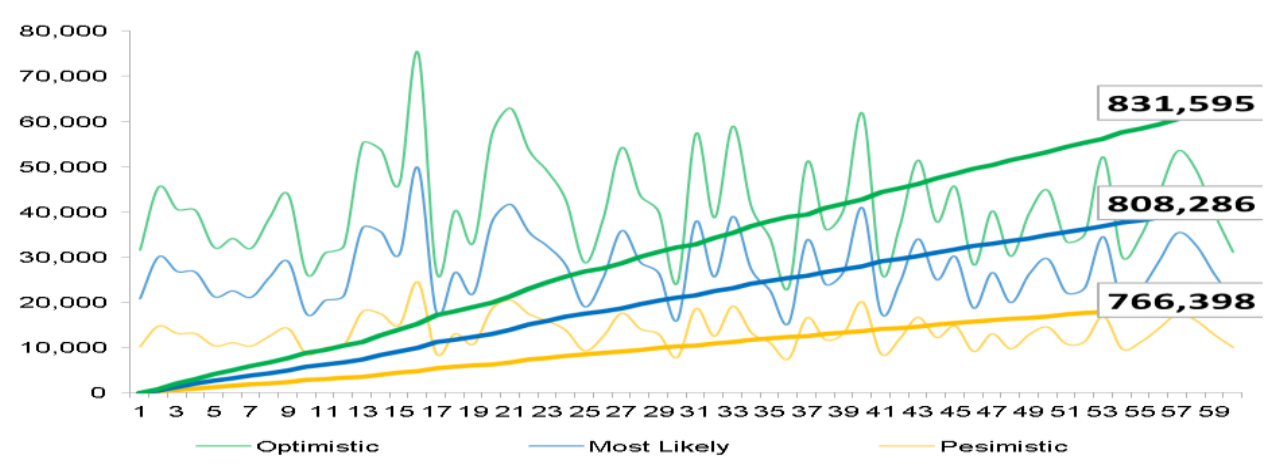

Figure 3 Simulation results of all risk scenarios of finished product in the warehouse

The output of this simulation is to compare the risk of production process failure in several scenarios. The best scenario results are shown in an optimistic scenario with $100 \%$ handling reliability and $0 \%$ product deterioration. If the selling price of product at GM Manufacturing is IDR $17,000,000 /$ ton, then for an optimistic scenario, which has a difference of 115 tons from the actual, the company can make savings of IDR 1,995,000,000 per month.

\section{Conclusions}

The dynamic system model developed describes the risk conditions of the failure of the production process. The model designed validated the actual results, which did not differ significantly from the simulation results. The risk of failure in the warehouse of finished products is based on the field and historical data, which are used to make the following models: the optimistic model, which is obtained from the minimum defect; the most likely model, which is obtained from the average defect; and the pessimistic model, which is 
obtained from the maximum defect. Each process in the warehouse is based on monthly historical data and then represented as a quantified dynamic system.

Several policy scenarios related to the risk of failure of the production process are tested to obtain a percentage of product defects each month. Exogenous variables from this simulation are the reliability of the product handling, the percentage of successful rework, and the percentage of products that deteriorate.

The simulation results show that the optimistic scenario has the smallest product defects of $0 \%$, and that the most likely condition is $1 \%$, while the pessimistic one is $4 \%$. The optimistic situation has a difference of 115 tons from the actual condition, so the company can make savings of IDR 1,995,000,000 per month.

The largest benefit comes from an optimistic scenario with IDR $226,480,000,000 /$ month; the most likely scenarios give a benefit of IDR $224,632,000,000 /$ month; and, finally, the pessimistic scenario gives one of IDR $217,413,000,000 /$ month.

\section{References}

Grösser, S.N., Reyes-Lecuona, A., Granholm, G., 2017. Dynamics of Long-Life Assets: From Technology Adaptation to Upgrading the Business Model. Switzerland: Springer

Hidayatno, A., Rahman, R., Muliadi, R., 2015. Policy Analysis of the Jakarta Carbon Mitigation Plan using System Dynamics to Support Decision Making in Urban Development Options for Policymakers. International Journal of Technology, Volume 6(5), pp. 886893

Kilibarda, M., 2013. Logistics Failures in Distribution Process. Logistics International Conference, Volume 114(1), pp. 247-252

Liu, C., Xie, Z., Sun, F., Chen, L., 2015. System Dynamics Analysis on Characteristics of IronFlow in Sintering Process. Applied Thermal Engineering, Volume 82, pp. 206-211

Liu, Z., Liu, X., 2018. Storage Reliability Assessment for the Stored Equipment Under Periodical Inspection. Advances in Mechanical Engineering, Volume 10(6), pp. 1-7

Moeis, A.O., Desriani, F., Destyanto, A.R., Zagloel, T.Y., Hidayatno, A., Sutrisno, A., 2020. Sustainability Assessment of the Tanjung Priok Port Cluster. International Journal of Technology, Volume 11(2), pp. 353-363

Poles, R., 2013. System Dynamics Modelling of a Production and Inventory System for Remanufacturing to Evaluate System Improvement Strategies. International Journal of Production Economics, Volume 144(1), pp. 189-199

Qiao-Lun, G., Tie-Gang, G., 2011. System Dynamics Analysis of RFID-EPC's Impact on Reverse Supply Chain. In: International Conference on Management Science and Engineering - Annual Conference Proceedings, Rome, Italy

Sterman, J.D., 2000. Systems Thinking and Modeling for a Complex World. Management. Volume 6(1), pp. 7-17

Suwandi, A., Zagloel, T.Y., Hidayatno, A., 2018. Conceptual Model of Failure Risk Control on Raw Materials Inventory System. In: IOP Conference Series: Materials Science and Engineering, Jakarta, Indonesia

Suwandi, A., Zagloel, T.Y., Hidayatno, A., 2020. Minimization of Pipe Production Defects using the FMEA method and Dynamic System. International Journal of Engineering Research and Technology, Volume 13(5), pp. 953-961

Suwartha, N., Berawi, M.A., Zagloel, T.Y.M., Surjandari, I., 2015. Enhancing the Quality of Products and Projects through Better Designs and Modeling. International Journal of Technology, Volume 6(5), pp. 718-721 